\title{
The research-led pedagogy in contemporary planning education
}

\author{
Bing Chen \\ Department of Urban Planning and Design, Xi'an Jiaotong-Liverpool University, Suzhou, China
}

\section{Email address:}

Bing.Chen@xjtlu.edu.cn

\section{To cite this article:}

Bing Chen. The Research-Led Pedagogy in Contemporary Planning Education. Education Journal. Special Issue: Interdisciplinary Researches in Environmental Design Education. Vol. 4, No. 1-2, 2015, pp. 1-9. doi: 10.11648/j.edu.s.2015040102.11

\begin{abstract}
This paper aims to explore the research-led pedagogy in contemporary planning education. A case study was conducted in the Department of Urban Planning and Design, Xi'an Jiaotong-Liverpool University, to show a range of teaching and learning methods which aimed to embed research into the academic experience, thereby facilitating students' active learning. The application of these new teaching models (e.g. integrated teaching across different modules, interdisciplinary workshops, field studies, summer undergraduate research projects, games, etc.), as a move away from the lecture-based approach to a hands-on approach, provides an opportunity for students to engage with some innovative concepts (e.g. sustainability, resilience, etc.) and explore their applicability and value in practice. It was found from this study that there is an urgent need to foster a research-led learning environment which can facilitate innovative educational practices or similar. Such an ongoing process can also help students deepen their understanding of the latest requirements of China's overall strategic development plans (e.g. the integrative development of urban and rural areas) and thereby cope with new issues arising in the urban-rural transformation. Since the host institution of this study (XJTLU) is itself a joint venture between Xi'an Jiaotong University China and the University of Liverpool UK, some findings from this case study reflect the differences of educational practices between the UK and China.
\end{abstract}

Keywords: Research-Led, Pedagogy, Planning Education, Active Learning, Curriculum

\section{Introduction}

Mirroring the magnitude and significance of the changing circumstances - social, technological, economic, environmental and political - in the new era, there is an urgent need to increase the capacity for resilience of today's cities. The concept of resilience, together with sustainability and other innovative concepts, is considered important in contemporary urban planning and design as an approach to the multifaceted nature of local and global challenges (e.g. [1], [2]). It also becomes a challenge to incorporate these concepts into the curriculum in planning education.

In the UK, the Royal Town Planning Institute (RTPI) has been engaged in a programme of radical evolution since 2001 . By acknowledging that effective planning cannot be delivered through governmental activity alone, the New Vision of Planning seeks to build the capacity within society and its institutions to take effective and relevant decisions so that the responsibility can be shared among all sectors [3]. To a great extent, urban planning and design is considered in this
New Vision as a 'value-driven' and 'action-oriented' collective activity which built environment professionals facilitate, but do not own or monopolise [3]. The New Vision of Planning also provides some core principles to encourage planners and designers to think beyond the scope of statutory systems [3]:

- 'Spatial - dealing with the unique needs and characteristics of places;

- Sustainable - looking at the short, medium and long term issues;

- Integrative - in terms of the knowledge, objectives and actions involved;

- Inclusive - recognising the wide range of people involved in planning'.

The above ideas have also been used to facilitate reform of the planning education system in the UK, which aims to nurture an inter-disciplinary learning environment that can promote 'critical thinking about space and place as a basis for 
action or intervention' [4]. Based on the review of changing circumstances in society, the profession and education, the RTPI Education Commission issued its final report in January 2003, which identified three key learning outcomes of contemporary planning education and training [4]:

- 'An understanding of what spatial planning is, and the skills that underpin it;

- An in-depth understanding of an area of specialism within spatial planning; and

- An assessment professional competence, that is, "fitness to practice"".

Although some academics argued that the RTPI Education Commission's report lacked specificity compared to the guidelines set by the Planning Accreditation Board (PAB) in the USA (e.g. [5], [6]), the general input requirements in the report left individual planning schools with more freedom to interpret the New Vision and thereby to develop and justify their own approaches (e.g. necessary knowledge, skills and value awareness that students should acquire by undertaking the programmes, area(s) of specialism, and the pedagogy, etc.) in line with their articulated educational philosophies. Reflecting the contingent and dynamic nature of planning activity, the indicative guidance, rather than a prescriptive one, allows the curriculum to be modified over time to cope with new issues arising from the process of 'making of place and mediation of space' [7]. To a large extent, by incorporating the concept of resilience - 'the degree to which various environments and systems can tolerate changing conditions and circumstances before adapting and reorganizing around a new set of structures and processes' as addressed by the AESOP (the Association of European Schools of Planning) - ACSP (the Association of Collegiate Schools of Planning) Joint Congress 2013 - into the changing profession of planning and the relevant education context, the dialogue between practice and the academy can be reconnected and increased [8].

Just like planning itself must always be prepared for change and use the best (but often imperfect) current information to make good quality decisions and chart a vision for the future of a place, spatial planning requires 'knowledge of how relationships in place and space both change and develop over time and are open to positive influence by creative planning' [7]. In return, the knowledge, skills and value components of a planning degree should not be static. It is important for all graduates to have the ability to both pursue and use new knowledge throughout their careers and have competence in cross-cultural communication $[6,9]$. As a result, the purpose of having initial planning education is only to provide 'a platform of understanding of the broad principles that govern planning operations, rather than about meeting an ever widening set of specific requirements' [7]. This paper intends to provide a deep insight into the given phenomenon, focusing particularly on an innovative research-led pedagogy at the undergraduate level and its usefulness on promoting explicit integration of knowledge, skills and values and thereby facilitating creative planning.

\section{Research-Led Pedagogy}

Research-led teaching, as well as its impacts on students' learning (both positive and negative), has been widely discussed in previous research (see [10], [11]). There is substantial evidence relating to the benefits of fostering a research-led learning environment in higher education institutions and the value of learning through research. Specifically, by serving as a route to high level personal and professional development in synthesis and reflection, a research-led pedagogy can provide students with not only subject-based and transferable knowledge, but also lifelong and adaptive learning capabilities, independence of thought, critical thinking, entrepreneurial skills, the ability to handle uncertainty and new problems and other important attributes which students need to engender [10] [12].

Research-led teaching often takes many different forms, reflecting the fact that different academics prefer to interpret and implement this concept from different dimensions, using different procedures, through different formats and to different extents, taking into account their intrinsically varying incentives. Among these approaches, the 'inquiry-based learning', where students are actively involved in the 'process' of research (e.g. research simulation activities, content dissemination, etc.) instead of being informed only of research content as a 'product', is considered useful to promote active learning in the built environment related disciplines [13-16]. It regards research as a process of edification and understands academic education as participation in research $[10,17]$. This creative, generative and reflective 'learning-by-doing' process also requires and develops higher cognitive capabilities and fosters innovation.

While on the other hand, research-led teaching should not be taken for granted as an indicator of quality teaching. In fact, compared with the functional approach that takes research as a learning tool to develop competencies for the knowledge society, the above approach is regarded more idealistic [17]. The mixed use of the 'functional approach' and the 'idealistic approach' in practice often results in ambivalences concerning the 'research-teaching nexus'. To stick to the idealistic approach (e.g. inquiry-based learning) and enhance the benefit to students, there is a need to nurture a kind of pedagogic (or even educational) reflection and research on academic education that is distinct from the one belongs to the functional approach [17].

Using the curriculum design in the Department of Urban Planning and Design (UPD) at Xi'an Jiaotong-Liverpool University (XJTLU) as an example, this paper explores how different models of teaching in the built environment disciplines can be linked to the research-teaching nexus and be devised around inquiry-based learning. It is important to note that fostering a research-led learning environment is an ongoing process and the following case study only shows some models that intend to embed research in the academic experience: 
- the 'Pedagogic Research-led Teaching',

- the 'Student-led Research-based Learning',

- the 'Research methodology Research-led Teaching', and

- the usual 'Academic Research-led Teaching' [9].

\section{Case Study: Research-Led Teaching Models in UPD at XJTLU}

As a joint venture between Xi'an Jiaotong University China and the University of Liverpool UK, Xi'an Jiaotong-Liverpool University (XJTLU) aims to become a research-led international university in China that is recognised for its unique features in learning and teaching, research, social service, and education management. A research-led pedagogy has been adopted by a range of disciplines at XJTLU in order to encourage active learning and thereby foster a culture of inquiry-based, independent learning in a world-class research environment.

Regarding contemporary planning education, the Department of Urban Planning and Design at XJTLU now offers a combined planning programme over three years at the undergraduate level, covering both spatial and specialist elements (referring respectively to spatial and specialist planning education addressed by the RTPI). Specific issues arising in the current planning practice in China (e.g. the so-called 'integrative development of urban and rural areas' under the fast urbanisation process) have also been taken into account in the curriculum design.

\subsection{Pedagogic Research-Led Teaching: Integrated Teaching Across Modules}

'Teaching itself, through reflective, critical pedagogy, should be treated as a valuable research base' and 'a very useful resource for research-led teaching' [9]. As a new programme, the undergraduate programme of B.A. in Civic Design in UPD at XJTLU serves as a good base to conduct teaching-related research and implement research-led teaching (see [18], [19]).

As shown in Fig. 1, all modules under the XJTLU UPD's combined planning education programme can be roughly categorised into three sectors: knowledge, skills, and planning and design competency. Departmental Learning and Teaching Committee meetings have been held regularly in order to review the programme as a whole and thereby keep the consistency of and reduce the unnecessary overlapping of teaching contents across different levels from a longitudinal perspective [19]. In addition, pedagogic research has been conducted to reinforce links between different modules at the same level and thereby allow students, from an integrative perspective, to implement knowledge, skills, and planning and design competency acquired from different modules.

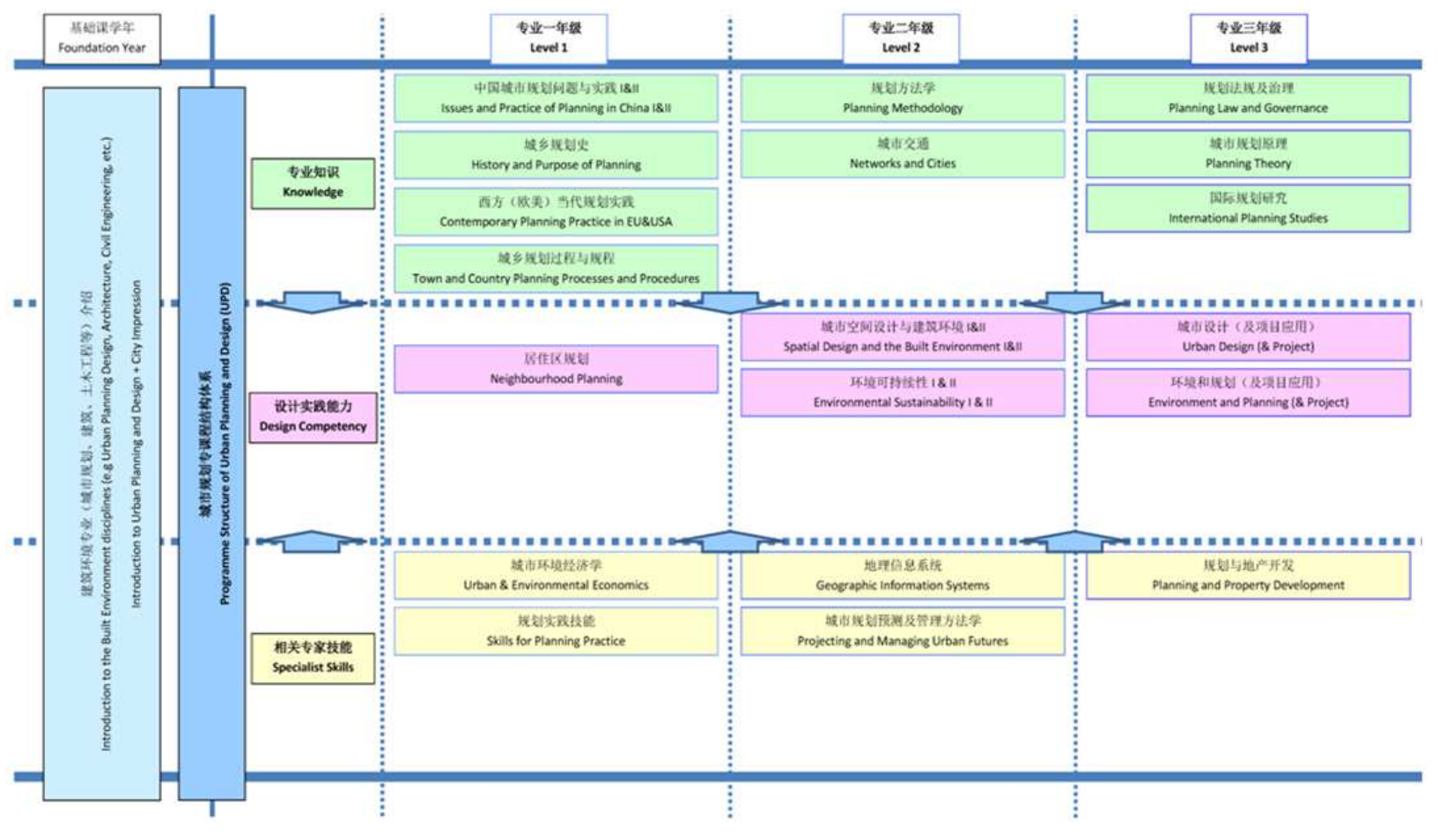

Figure 1. Curriculum Design at XJTLU UPD (adapted from [19])

At the Undergraduate Level 2, for example, three modules - 'Environmental Sustainability', 'Spatial Design and the Built Environment' and 'Geographic Information Systems' have been linked together. The original requirements of these three module assignments are as following:

In the module 'Environmental Sustainability', students have been required to work in groups to provide an environmental appraisal for a given district (which is relatively large) and conduct an on-site survey to collect relevant information. Then based on the overall development framework, each individual chooses a specific environmental planning issue (e.g. landscape, water, transport, waste, etc.) 
working on its deeper analysis independently.

In the module 'Spatial Design and the Built Environment', students have been required to work in groups to provide design proposals for a chosen site (which is relatively small). After reaching an agreement on the master plan, each individual is assigned to a smaller site in order to detail the place individually.

The module 'Geographic Information Systems (GIS)' currently requires students to present and analyse the spatial information using GIS maps.

By using an identical district for all three modules (i.e. the site being used for spatial design is located within the district being used for environmental assessment), it is possible to foster an iterative teaching and learning process (Fig. 2). Sustainability principles and relevant skills (e.g. Environmental Impact Assessment) addressed in the environmental sustainability lectures, workshop and surgeries can be efficiently fed into the studio projects run in parallel helping interpret policy or regulations, identifying environmental issues to be addressed in the design brief, deciding project specification based on baseline or benchmark studies, predicting impacts and formulating mitigation measures, and proposing and evaluating different design strategies from a socio-economic perspective (e.g. participatory decision-making and Cost-Benefit Analysis, etc.). By the end of one round of information flow, evaluation of the design proposals can help detect flaws in the existing policies, plans or programmes with regard to environmental sustainability and thereby provide valuable suggestions on their further improvement. This can then serve as the starting point of the next round of 'using research to inform design' action. The GIS module provides technical support to facilitate knowledge transfer throughout the above activities.

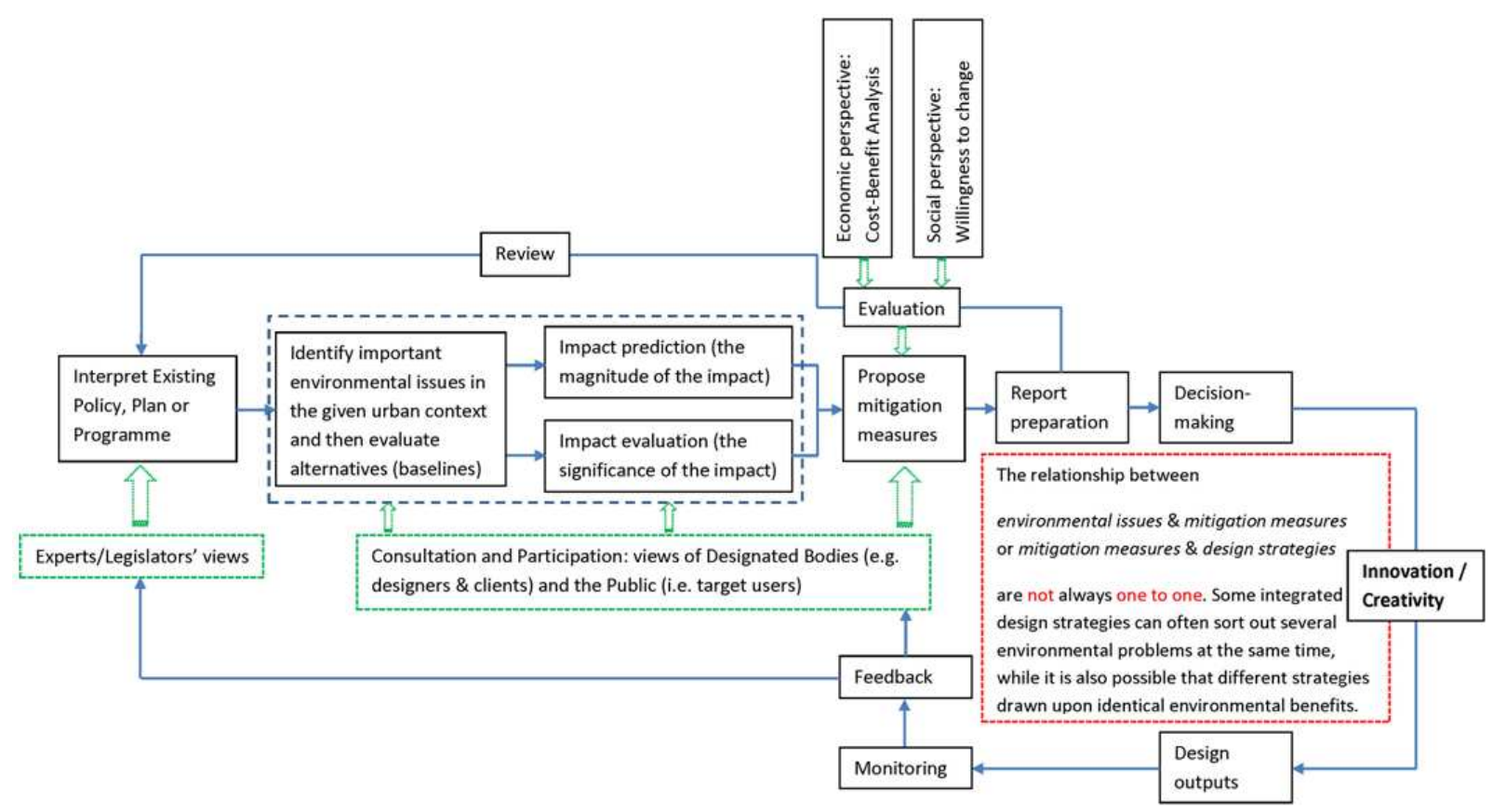

Figure 2. Information flow - one-round of 'using research to inform design' (Source: [18])

Rather than asking students to spend time and energy on three independent projects resulting in a superficial understanding of each, this integrative pedagogy allows students to gain an in-depth insight into a given urban context and, meanwhile, reducing the unnecessary overall workload. Another important learning outcome of this integrated design project is to help students develop skills to 'enquire critically and think systematically about problems in a way that allows them to explore the associated complexity' [20]. Based on feedback from students and a comparative study with the traditional pedagogic method (i.e. modules are delivered to students independently), it was found that this Pedagogic Research-led Teaching approach can promote explicit integration of knowledge, skills and values and can challenge compartmentalized thinking in urban planning and design (Fig. 3 shows the output samples). Furthermore, such an integrated working strategy with both group and individual work reflects the real working environment in urban planning and design and can thereby provide students with a brief glimpse of the ongoing urban planning and design process from 'Getting started', 'Appreciating the context' and 'Creating the urban structure/marking the connections' (Group Work) to 'Detailing the place' and 'Following up' (Individual Work) as addressed in the 'Urban Design Compendium 2: Delivering quality places' [21].

It is important to note that, although the above pedagogic approach can help students better understand the interrelationship between planning and design, it needs to be applied with certain prerequisites. For instance, in the Chinese context, planning and design activities can only overlap on certain levels of the planning hierarchy - using detailed plans to inform urban design or vice versa. Also, it is important to differentiate the assessments of three modules according to their own learning comes. 


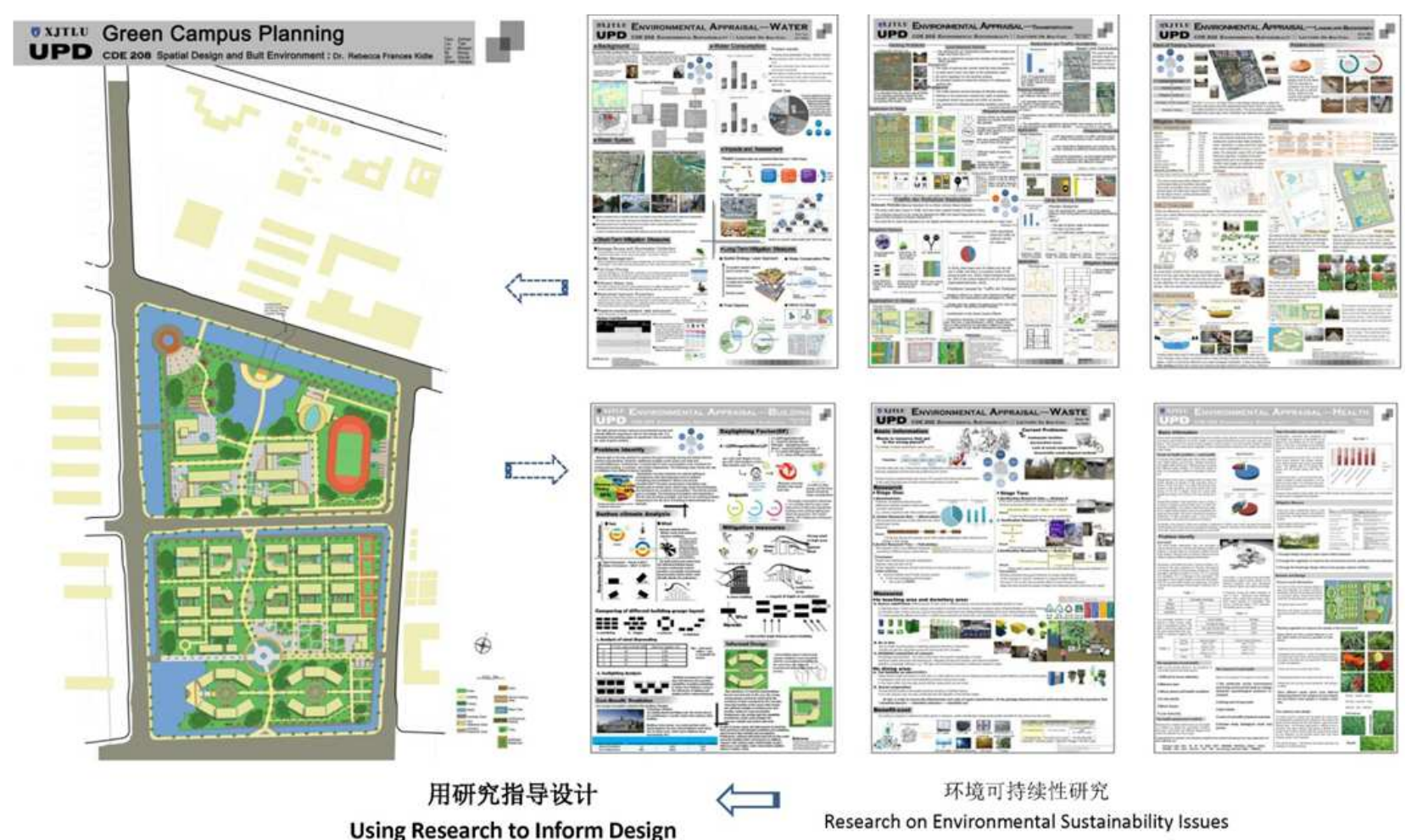

Figure 3. Students'learning outputs - coursework samples (Level 2 Semester 1)

\subsection{Student-Led Research-Based Learning: Interdisciplinary Workshops \& SURF}

As mentioned earlier, research-led teaching generally implies a student-centred approach to learning via research. The famous Chinese educator Confucius indicated that 'by three methods we may learn wisdom: first, by reflection, which is noblest; second by imitation, which is the easiest; and third, by experience, which is the most bitter'. In terms of planning education, particular attention has been paid to the innovative ways of engaging students with the important planning and design issues (e.g. sustainability, resilience, etc.) arising in the contemporary urban-rural transformation, mirroring a movement of higher education from the traditional lecture-based approach to a more hands-on approach.

The international workshop 'Critical Planning for Chinese Cities' (CPCC) held at XJTLU UPD every year in collaboration with the International Laboratory of Architecture and Urban Design (ILAUD) is tailored to address the above concerns. The first event in 2012, 'Designing the future of the system of rural villages around Tai Lake in Suzhou', brought academics and students from all over the world (namely Ecole Polytechnique Federale de Lausanne, South China University of Technology, Suzhou University of Science and Technology, the University of Ferrara, the University of Liverpool, the University of Newcastle, Wuhan University, etc.) to discuss the topic 'urban and rural conflicts' in the context of China's urban transition [22]. Eight themes were provided to inspire students' creative thinking on the planning on the edge (i.e. urban-rural fringes): 'a quality public realm', 'accessibility and economics', 'agricultural landscapes', 'place identity and tourism', 'conserving Dongcun's heritage', 'improving public amenities', 'green and blue systems' and 'transition towns'.

Students coming from different built environment disciplines (e.g. Urban Planning and Design, Architecture, Landscape Architecture, etc.) and different education backgrounds (e.g. the traditional Chinese education system, the joint education system between West and East, etc.) were required to form multi-disciplinary teams, then work together on the given sites under the supervision of a group of international academics (including scholars from architecture, urban planning and design, landscape architecture, urban economics, etc.). Each team needed to conduct an on-site survey, define a place-based development strategy supported by design simulations and visualize their proposals through graphs, sketches and texts within ten days (Fig. 4-5 show the output samples). By working in a multi-disciplinary environment like this, students could achieve a holistic appreciation of the important urban-rural development concerns (e.g. sustainability, resilience, etc.) and improve their understanding of the importance of inclusive teamwork and the role they and others will play in relation to each other in the development of sustainable practices and the procurement of resilient urban-rural fringes [23]. This student-led research-based learning process itself also provides an opportunity to explore how different disciplines contribute to problem and solutions in a collaborative design process [18]. 

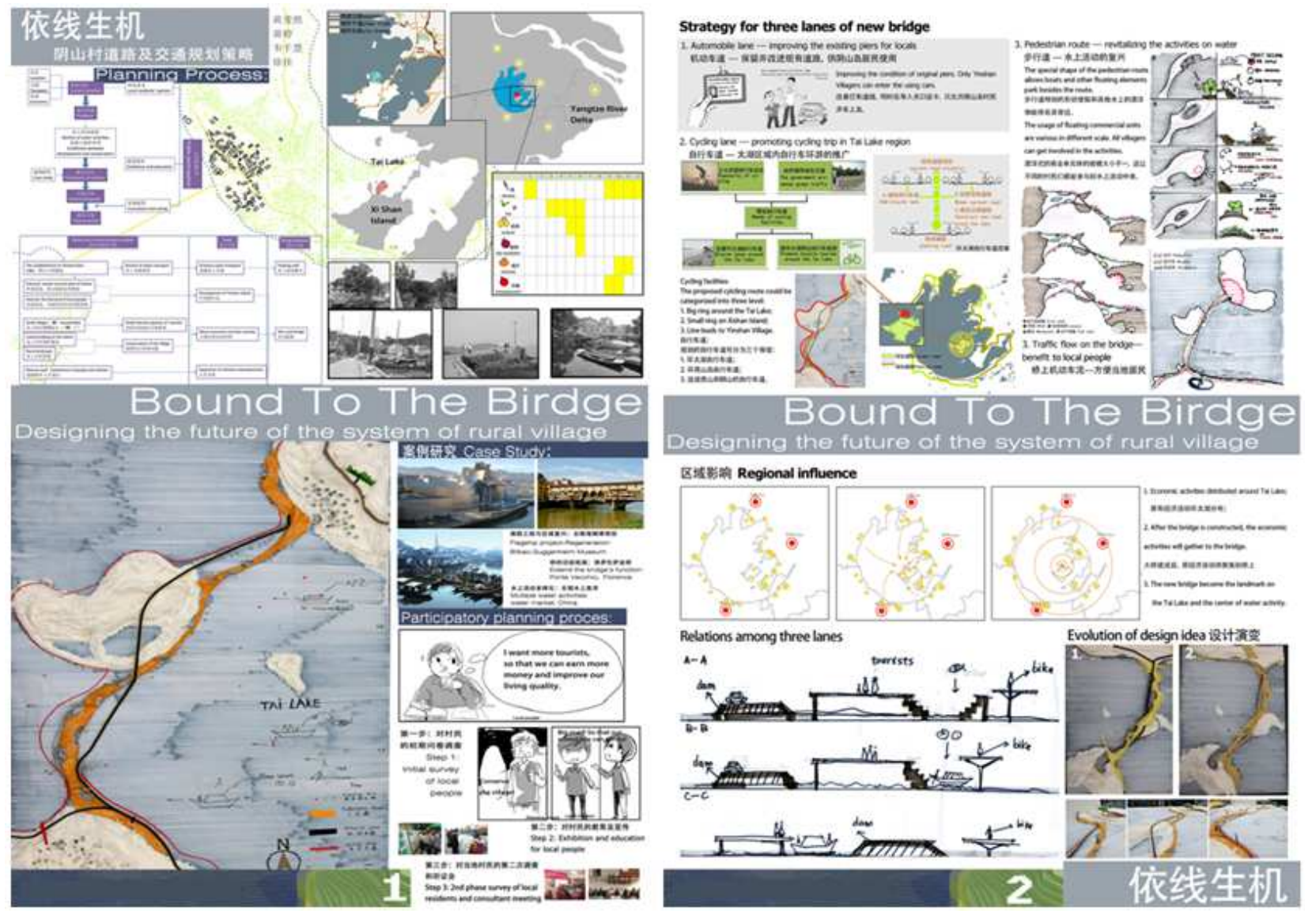

Figure 4-5. Students' Proposals on 'accessibility and economics'.

Apart from facilitating collaborations across different universities, this workshop provides an insight into the advantages and disadvantages of different education systems and the corresponding pedagogies. Observation on the workshop has shown that students from traditional Chinese universities excel at physical space design and relevant skills (e.g. sketch, CAD, etc.), but lack the ability to efficiently link the space resources with local sustainable development (including managing social, economic and environmental concerns from the short-, medium- and long-term perspectives). Students from XJTLU UPD and other international universities have a better understanding of sustainable, integrative and inclusive planning principles, but their skills of presenting critical thinking about place making need to be improved. Since neither approach can fully meet the requirements made in the China's overall strategic development plan [24], it is important for these academic institutions to learn from each other and then develop and justify their own pedagogic approaches in line with their articulated educational philosophies. Cross-university activities, such as international workshops, are certainly of benefit to this.

XJTLU is committed to enhancing student-led research activities. In addition to holding international workshops, XJTLU UPD offers opportunities for selected undergraduate students to work on research projects during the summer through the Summer Undergraduate Research Fellowship
(SURF) programme. This aims to introduce undergraduate students to research, stimulating their active research interest and creativity, and developing their practical skills. Research output from one of the SURF projects at XJTLU UPD 'Seeking new self-identity for landless farmers during the urban-rural integration process' - has been accepted and included in the 2012 Congress of Academic Committee of Foreign Studies in Urban Planning (ACoFSUP) proceeding.

\subsection{Research Methodology Research-Led Teaching: Field studies \& Games/Quiz}

The host region of XJTLU - China-Singapore Suzhou Industry Park (SIP) - is a country-level administrative area built in 1994. It is considered a prototype for subsequent modern industrial parks in China such as the Sino-Singapore Tianjin Eco-City built in 2007. Compared to the modern SIP, the old town of Suzhou, located in the west of SIP, is well known for its classical gardens which are a UNESCO World Heritage Site and the morphology shaped by its unique water systems. To summarise, the Suzhou city (including the preserved old town and the newly developed SIP) serves as a good scenario to study planning issues arising in China's urban transition. In return, local communities and the region itself have been used by XJTLU UPD undergraduate programme as a locus of exploratory activities. For instance, the student-led SURF project mentioned earlier looks at issues related to social capital and the community 
development for resettlements of displaced farmers during the urban-rural integration process. However, as indicated by Mumford (1938, cited in [25]) 'before the resources and activities of a region are treated as abstract subjects, they should be understood and felt and lived through as concrete experiences'.

To successfully achieve the above objective, students are encouraged to conduct more field studies, actively participate in shaping local communities and regions, and then experientially explore the challenging issues of sustainability, resilience and other principles in the given urban context. Besides helping students understand the bottom-up approach in contemporary planning, it requires students to come up with innovative methods to implement the inclusive principle in the participatory decision-making processes. For instance, in the module 'Neighborhood Planning', in order to efficiently communicate the spatial features with local residents at different ages (especially old and young), students use LEGO bricks to build mock-ups and illustrate the changing characteristics of a place in the short-, mediumand long-term. This innovative thinking on cross-cultural communication has been further developed in the teaching-learning activities later in the module 'Planning and Property Development', where an adapted model of the game Monopoly has been introduced to help students understand economic issues relating to the real estate development and the role played by different stakeholders in the supply chain.

This research methodology research-led teaching is also of benefit to the implementation of adaptation planning which refers to the ways in which knowledge (or more precisely, knowledge diffusion) alters local behavior [26]. Previous research has indicated that it is people's awareness of sustainability issues and willingness to change their lifestyles towards greater environmental sensitivity that will decide how far they want to go to save energy, reduce carbon dioxide emissions and recycle waste and so on [18] [26]. Changes in people's behavior can also help avoid some unexpected outcomes in the process of tackling climate change, for instance the one indicated in the Khazzoom-Brookes postulate - 'energy efficiency reduces the price to the consumer who then will either increase demand through price elasticity or choose to spend their increased disposable income on other energy-consuming goods and services' [27].

However, the 'over simplistic, mechanistic causal postulation between information provision and behavioral change' have been criticised in previous research [28] and some new approaches (e.g. tools borrowed from related disciplines) are emerging in response to the challenges [29].

To engage others to re-evaluate everything they do with a broader public purpose in mind, students studying civic design or other built environment related disciplines should be equipped with not only professional competencies (including knowledge and skills) but also responsible ethics and capabilities (e.g. ecological literacy) as the first step in the transformative learning process [18] [25]. To achieve this objective, the online Ecological Footprint Quiz [30] has been introduced to help students understand the relationship between their own per-person resource demand on the Earth's biosphere in a given year and the available biological capacity of the planet in that year. Then a student-led campaign - 'Greening the Campus' - has been launched as part of the problem-oriented teaching and learning plans of the module 'Environmental Sustainability'. It intends to link new initiatives (e.g. education for sustainability and resilience) to local priorities and to identify and generate locally-relevant knowledge and awareness. This was inspired by the practical lessons drawn from the case studies of urban climate adaptation planning in Durban, South Africa, and in Quito, Ecuador - even highly resource-constrained cities were able to alter their practices and this would be primarily driven by locally-determined goals and values [26]. As indicated by RTPI [7], planning activity is necessarily fashioned within a particular set of social and professional values so that it is essential that students are aware of how values affect planning decisions, and thereby acquire the lifelong habit of reflecting upon their own values and the effect of these upon their own planning work [6].

It is hoped that this hands-on approach will help students better understand a fact that - in reality, educating other stakeholders into more genuinely collaborative roles does not happen spontaneously in a participatory decision-making environment; instead, these people need to be provided with understanding about the need for change, and with tools to help them change.

\subsection{Academic Research-Led Teaching}

The Academic Research-led Teaching is not the focus of this paper, given the fact that different models of using academic's ongoing research projects as teaching materials have been widely applied in planning education.

\section{Discussion \& Conclusion}

Based on the case study above, it can be seen that the complex multi-disciplinary nature of urban planning and design serves as the perfect area of practice to apply a broad range of effective pedagogies that may require advanced, high-level, analytical, holistic, hands-on approaches to bring about real solutions to society. As indicated by Banai, 'urban sustainability informs and is enhanced by the pedagogic principles that have emerged with discussions of teaching and learning effectiveness of alternative educational models' [25]. This idea can also be comparably applied to the urban resilience-education nexus. Such kind of nexus suggests that reciprocity is beneficial - the theory and practice of planning sustainable or resilient cities and regions is also enhanced by certain pedagogic procedural principles from classroom to community. However, it is also important to note that these pedagogic principles are more than mere procedural abstractions if informed substantively by the values of sustainability, resilience or other concepts. To a certain extent, they are aligned with these values and their nexus has implications for contemporary planning education and 
practice [25].

By engaging students actively as independent learners in a culture of research in which learning is integrated into the ongoing process of scholarship, research-led teaching can effectively facilitate integrated understanding of broad matters of principle (e.g. sustainability, resilience, etc.) and equip students with necessary values and diverse skills as required by RTPI [7]. The research-led teaching methods discussed in this paper only intend to show one way of embedding research in the academic experience at XJTLU. While it does not mean they are the best or only ways to do so. It can be found from the case studies that the relationship between the research-led pedagogic strategies and the teaching and learning activities is not always one to one. Some research-led pedagogic strategies can often be integrated in identical teaching and learning activities, while it is also possible that one research-led pedagogic strategy needs to be successfully applied through several teaching and learning activities. Another important concern that should be taken into account by academics who would like to take the research-led teaching approach is that sometimes it might involve the danger of exploitation if students are actively engaged in the research while they have not been fully acknowledged in subsequent publications [13].

\section{Acknowledgements}

Thanks are due to all colleagues who have been committed to the development of relevant pedagogy and curriculum in UPD at XJTLU. This research is guided/supported by the 2013 Jiangsu Philosophy and Social Sciences Research Funding Programme (Ref: 2013SJD880110).

\section{References}

[1] C. Whitzman. "Reinventing Planning Education". Australian Planner (2009) 46 (1): pp. 14-21

[2] C. Brown, J. Claydon and V. Nadin. "The RTPI's Education Commission: Context and Challenges". The Town Planning Review (2003) 74 (3): pp. 333-345

[3] RTPI (Royal Town Planning Institute). “A New Vision for Planning: Delivering sustainable communities, settlements and places", 2001. [Online] Available at: $<$ http://www.rtpi.org.uk/education-and-careers/learning-aboutplanning/what-planning-does/rtpi-vision-for-planning/> [assessed 10 March 2014]

[4] RTPI (Royal Town Planning Institute). "RTPI Education Commission Report". London: RTPI, 2003

[5] P. Batey, R. Boyle, A. Motte, P. Ache, S. Pepper and T. Claydon. "Comments on the RTPI Education Commission's Report and Its Implications for Planning Education". The Town Planning Review (2003) 74 (4): pp. 355-369

[6] D. Reeves. "Future scoping - developing excellence in urban planners". Australian Planner (2009) 46 (1): pp. 28-33

[7] RTPI (Royal Town Planning Institute). "Policy Statement on Initial Planning Education", 2012. [Online] Available at:
$<$ http://www.rtpi.org.uk/media/1403721/microsoft_word_- po licy_statement_on_initial_planning_education_20 $\overline{1} 2$.pdf $\overline{ }$ [assessed 10 March 2014]

[8] G. Ellis, B. Murtagh and L. Copeland. "The Future of the Planning Academy (Report)". Belfast: Queen's University Belfast and RTPI, 2012.

[9] A. Miller, J. Sharp and J. Strong (ed.). "What is research-led teaching? Multi-disciplinary perspective". London: CREST, 2012 .

[10] M. Deakin. "Research Led Teaching: A review of two initiatives in valuing the link between teaching and research". Journal for Education in the Built Environment (2006) 1 (1): pp. 73-93

[11] M. Healey. "Linking Research and Teaching to Benefit Student Learning". Journal of Geography in Higher Education (2005) 29 (2): pp. 183-201

[12] M. Roach, P. Blackmore and J.A. Dempster. "Supporting High-Level Learning through Research-Based Methods: A framework for course development". Innovation in Education and Teaching International (2001) 38 (4): pp. 369-382

[13] A. Brew. "Enhancing the quality of learning through research-led teaching". In: HERDSA 2002 Conference Proceeding, 2002 [Online] Available at: $<$ http://finntrack.co.uk/education_sub/10.1.1.94.2723.pdf $>$ [assessed 10 March 2014]

[14] A. Brew. "Teaching and Research: New relationships and their implications for inquiry-based teaching and learning in higher education". Higher Education Research \& Development (2003) 22 (1): pp. 3-18

[15] M. Healey. "Linking Research and Teaching: exploring disciplinary spaces and the role of inquiry-based learning". In: Barnett R. (ed.) (2005) Reshaping the University: New Relationships between Research, Scholarship and Teaching. McGraw Hill/Open University Press, 2005 pp. 67-78

[16] R. Griffiths. "Knowledge production and the research-teaching nexus: the case of the built environment disciplines". Studies in Higher Education (2004) 29 (6): pp. 709-726

[17] M. Simons and J. Elen. "The 'research-teaching nexus' and 'education through research': an exploration of ambivalences". Studies in Higher Education (2007) 32 (5): pp. 617-631

[18] B. Chen. "Education for Sustainable Architecture: Professional competencies and responsible ethics". In: Bovati M., Caja M., Floridi G. and Landsberger M. (ed.) Cities in Transformation Research \& Design: Ideas, Methods, Techniques, Tools, Case Studies (Volume II). Padova: Il POLIGRAFO, 2014. pp. 1078-1086.

[19] B. Chen. "Planning Education for Sustainable City Transformation: The programme design and education reform in the XJTLU Department of Urban Planning and Design". In: China Urban Planning Education Network and School of Urban Design (ed.) Humanistic Planning Creative Transformation: Proceedings of China Urban Planning Education Conference 2012. Beijing: China Architecture and Building Press, 2012. pp. 360-367

[20] C.S. Hayles and S.E. Holdsworth. "Curriculum Change for Sustainability". Journal for Education in the Built Environment (2008) 3 (1): pp. 25-48. 
[21] English Partnerships \& The Housing Corporation. "Urban Design Compendium 2: Delivering quality places". London: Llewelyn-Davies, 2007.

[22] J. Friedmann. "China's Urban Transition". Minnesota: the University of Minnesota, 2005.

[23] L. Bird. "Rebuilding resilience: the education challenge", 2009 [Online] Available $<$ http://www.iiep.unesco.org/fileadmin/user_upload/Info_Serv ices_Newsletter/pdf/eng/2009/2009_1En.pdf $>$ [assessed 10 January 2014]

[24] Y. Wei and M. Zhao. "Advancing Normative Urban Planning Education in China: A study of educational institutions and urban planning curricula”. China City Planning Review (2009) 18 (3): pp. $42-49$

[25] R. Banai. "A Note on Urban Sustainability-Education Nexus. The Journal of Sustainability Education", 2012. [Online] Available

at: $<$ http://www.jsedimensions.org/wordpress/content/a-note-on-u rban-sustainability-education-nexus_2012_03/> [assessed 10 May 2014]
[26] J. Carmin, D. Roberts and I. Anguelovski. "Planning Climate Resilient Cities: Early lessons from early adapters". Paper prepared for the World Bank, 5th Urban Research Symposium 'Cities and Climate Change', Marseille, France, 2009.

[27] S. Sayce, L. Ellison and P. Parnell. "Understanding investment drivers for UK sustainable property". Building Research \& Information (2007) 35 (6): 629-643

[28] J. Salter. "Disasters as Manifestations of Vulnerability". The Australian Journal of Emergency Management (1995) 10 (1). [Online] Available $<\mathrm{http} / /$ search.informit.com.au/documentSummary; $\mathrm{dn}=40476$ 3441855044;res=IELHSS $>$ [assessed 10 March 2014]

[29] L. Robinson. "Education for resilience: Community safety communication for natural hazards". A paper prepared for the NSW State Emergency Service, 2003. [Online] Available at: $<\mathrm{http} / / /$ www.enablingchange.com.au/Resilience_and_risk.pdf $>$ [assessed 10 March 2013]

[30] Global Footprint Network (GFN). "Ecological Footprint Network: Advancing the Science of Sustainability". [Online]. $<$ http://www.footprintnetwork.org/> [05 March 2014] 